\title{
Pretreatment With Transmyocardial Revascularization Might Improve Ischemic Myocardial Function Performed With Cell Transplantation
}

\author{
Yanmei Wang, MS; Hongmei Tang, PhD; Dong Wang, PhD; Ruofan Li, MB; \\ Yilong Dong, PhD*; Wei Liu, PhD; Xiaodong Zhang, PhD*
}

\begin{abstract}
Background Cells transplanted into the myocardial infarct areas might be lost because of the lack of blood supply to these myocardium areas. The hypothesis that pretreatment with angiogenic therapy induced by transmyocardial revascularization (TMR) might improve ischemic myocardial function, followed by cell transplantation was tested.

Methods and Results After the ligation of the left anterior descending coronary artery, rats were treated with TMR. Two weeks, embryonic stem cells were transplanted into an injured heart. Four weeks after cell transplantation, cardiac function was assessed by homodynamic measurements. Capillary density and infarct size in the infarct myocardium were measured by using a previous experimental method. Graft histology and morphology was also evaluated. Four weeks after the operation, myocardial infarct (MI) rats treated with TMR and cell transplantation showed significantly higher cardiac function in hemodynamic measurements $(p<0.01)$ than that of MI rats receiving cell transplantation or TMR alone. A significant increase in capillary density and reduction in infarct size was observed in the MI rats that received a combined therapy $(\mathrm{p}<0.01)$.

Conclusion Pretreatment of an infarct region of the heart with angiogenesis induced by TMR can enhance the efficacy of a cell graft and attenuate the progression of cardiac dysfunction in the rat model. (Circ J 2006; 70: $625-630)$
\end{abstract}

Key Words: Cell transplantation; Myocardial infarction; Transmyocardial revascularization

I $\mathrm{n}$ recent years, embryonic stem cell transplantation has emerged as a novel approach for the generation of viable myocardial cells through replacement or regeneration, which can arrest or reverse ventricular remodeling and improve myocardial function 1,2 However, the death of some parts of grafted cell can occur after grafting into injured hearts, largely because of ischemia? The loss of grafted cells may decrease the efficacy of cellular cardiomyoplasty. On this basis, the formation of microvessels in infarct myocardium seems to be another important target for the treatment of myocardial infarction (MI). Transmyocardial revascularization (TMR) has proven to be effective in the refractory angina of MI because of its angiogenic effect. TMR, representing a potentially important process of increasing perfusion to infarct myocardium, can become a useful assistant for cell transplantation. We demonstrated that angiogenic pretreatment in infarct areas with TMR can enhance cardiac function prior to cell transplantation.

(Received June 24, 2005; revised manuscript received January 5, 2006; accepted February 24, 2006)

Departments of Anatomy, Histology and Embryology, *Pharmacology, Institute of Basic Medical Sciences, Chinese Academy of Medical Sciences, Peking Union Medical College, Beijing, China

Mailing address: Xiaodong Zhang, PhD, Department of Anatomy, Histology and Embryology, Institute of Basic Medical Sciences, Chinese Academy of Medical Sciences, 5 Dong Dan San Tiao, Beijing 100005, China. E-mail: xiaodong5806@sina.com.cn

\begin{abstract}
Methods
Animal Preparation

Male Wistar rats were obtained from the Laboratory Animal Center of the Chinese Academy of Medical Sciences. All animal experiments were approved by the Laboratory Animal Center of the Chinese Academy of Medical Sciences.
\end{abstract}

\section{Preparation and Label of Embryonic Germ Cells (EGs)}

The isolation and culture of EGs originates from the genital ridges in Wistar rat embryos at 10.5 days post coitum (d.p.c). Briefly, EGs were cultured in Dulbecco's Modified Eagle Medium (DMEM, Sigma) on methodically inactive 12.5 d.p.c Wistar rat embryonic fibroblast feeder cells. The medium was supplemented with $15 \%$ fetal bovine serum (Hyclone), 0.1-mmol/La-mercaptoethanol (Sigma), and $10^{3} \mathrm{U} / \mathrm{ml}$ recombinant mouse leukemia inhibitory factor (LIF, Chemicon), $10 \mathrm{ng} / \mathrm{ml}$ recombinant stem cell factor (SCF, R\&D systems) and $50 \mathrm{IU} / \mathrm{ml}$ penicillin, $50 \mu \mathrm{g} / \mathrm{ml}$ streptomycin (Calbiochem). Colonies of tightly packed alkaline phosphatase-positive (ALP-positive) EGs were present after 9 days in culture. To initiate differentiation, EGs colonies were dispersed with trypsin and resuspended in the medium without LIF or SCF. They were cultured by using the hanging-drops method (400-450 cells per $20 \mu \mathrm{l})$ for 3 days. The resulting embryonic bodies were then seeded into $100-\mathrm{mm}$ cell culture dishes for another 5 days at $37^{\circ} \mathrm{C}$ in a $98 \%$ humidified atmosphere with $5 \%$ carbon dioxide. Spontaneously beating cardiomyogenic clusters were dissected by using a sterile micropipette and then 


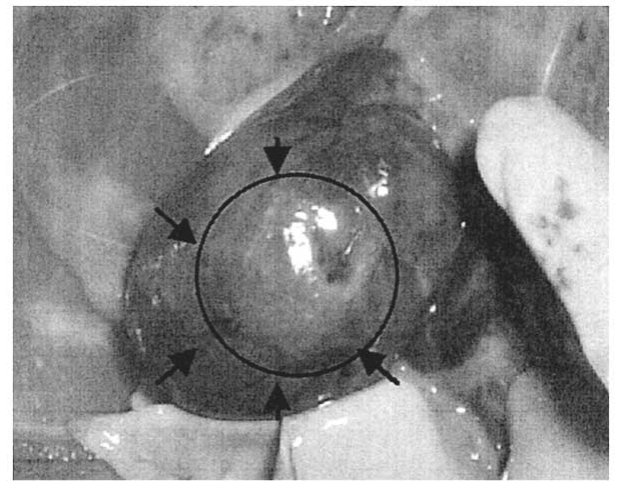

Fig 1. Transmyocardial channels at 4, 6, 8, 10, 12 o'clock sites were created at 5-mm intervals at the myocardial infarct border.

transferred into 6-well cluster plates for 2 days.

Before transplantation, the cells dissected from beating clusters were transfected with enhanced green fluorescent protein (GFP) genes to identify the survival of implanted cells. Plasmids with a human cytomegalovirous promoter driving GFP gene $(5.3 \mathrm{~kb})$ and the GenePORTER transferction reagent were obtained from Gene Therapy System (San Diego). Cultured cells were replated in 6-well cluster plates and cultured to $60-90 \%$ confluence on the day of transfection. The GFP plasmid DNA ( $2 \mu \mathrm{g})$ was added to each well for 2 days. Transfection efficiency detected by fluorescent microscopy was more than $90 \%$.

After 11 days of culture via the hanging drops method (without conducting the micopipette dissection of a beating cell) the cells were analyzed by using immunofluoresence. Briefly, the sample cells were fixed in acetone for $10 \mathrm{~min}$. Non-specific binding was blocked by incubation in $1 \%$ bovine serum albumin in phosphate-buffered saline (PBS) and then reacted with rat anti-a-myosin heavy chain ( $\mathbf{a}$ MHC) (major histocompatibiity complex monoclonal antibodies (Berkeley Antibody, Richmond, CA, USA) for $1 \mathrm{~h}$. After washing with PBS, sections were incubated with a goat anti-rat conjugated fluorescein $\operatorname{IgG}$ for a-MHC 9 (Pierce Chemical). Flow cytometry revealed that $32 \pm 1.1 \%$ ( $n=5$ runs) of EGs were positive for cardiac $\alpha$-MHC. This result demonstrated that EGs are able, at least a portion of them, to differentiate into cardiac-like cells after 10 days in culture.

\section{Model}

Rats underwent ligation of the left anterior descending coronary artery. In brief, rats were anesthetized with ketamine hydrochloride injection $(1.25 \mathrm{mg} / 100 \mathrm{~g})$ and incubated and mechanically ventilated at $90 \mathrm{breaths} / \mathrm{min}$. The heart was exposed via a left throacotomy incision and the left anterior descending coronary artery was ligated. The thoracotomy was then closed in layers, and the rats were allowed to recover under supervision.

\section{TMR and Cell Transplantation}

After coronary ligation, surviving myocardial infarct rats $(n=24$ in MI) were treated with transmyocardial mechanical revascularization by using a $1-\mathrm{mm}$ diameter needle (Hearten Medical, Tustin, CA, USA). Five drilling transmyocardial channels at $4,6,8,10,12$ o'clock sites were created at 5-mm intervals at the myocardial infarct border (Fig 1). They closed up soon and were full of blood after the procedure. Two weeks after TMR, $3 \times 10^{5}$ culture cells in $30 \mu 1$ medium $^{5}$ were injected with a sterile microinjection into injured heart at 3 different sites, 2 at the infarct myocardium border and 1 in the infarct area. Survivals of rats were evaluated in all groups during a 4-week follow-up period. All experimental rats were divided 4 groups: (1) MI rats treated with TMR and cell transplantation $(\mathrm{MI}+\mathrm{T}+\mathrm{C}$; $\mathrm{n}=8)$; (2) MI rats treated with cell transplantation $(\mathrm{MI}+\mathrm{C}$; $\mathrm{n}=8$ ); (3) MI rats treated with TMR (MI+T; $=8$ ); and (4) MI rats injected with medium only (MI; $n=8)$.

\section{Determination of Left Ventricular Function}

Hemodynamic measurements were performed in vivo with a modification of a method described previously5 Briefly, survivaled rats in the total group were anesthetized again with pentobarbital $(60 \mathrm{mg} / \mathrm{kg}$ ) before (baseline) and 4 weeks after operation. A carotid artery was isolated and cannulated with a $3 \mathrm{~F}$ high-fidelity microtip catheter connected to a pressure transducer. The catheter was carefully advanced into the left ventricle (LV). Left ventricular systolic pressure (LVSP) and left ventricular end-diastolic pressure (LVEDP), the maximum rate of LVSP rise $( \pm \mathrm{dP} / \mathrm{dtmax})$ were monitored and recorded on a chart strip recorder. Rats were allowed to breathe spontaneously during homodynamic measurements.

\section{Weight Parameters and Infarct Size}

After homodynamic measurements, the rats were killed by a lethal dose of pentobarbital and their heart and lungs were rapidly excised. The heart and LV (including the septum) were weighted and normalized for bodyweight. The ratio was calculated as an index of hypertrophy. Then, the LV was quickly embedded in tissue-freezing medium, and partial $6 \mu \mathrm{m}$ transverse slices were dissected and fixed in acetone at $4^{\circ} \mathrm{C}$ for $10 \mathrm{~min}$ subsequently. After being stained with hematoxylin and eosin, slices were placed under a video microscope with a 20 -fold enlargement lens. The endocardial and epicardial circumferences of the infarct tissue and that of the LV were determined by using image analysis software (Cyberview, Cervus International, and Courtaboeuf, France). The MI size (fraction of the infarct LV) was calculated as the average of all slices and expressed as a percentage of length. Infarct size was calculated by dividing the sum of the planimetered endocardial and epicardial circumferences of the infarct area by the sum of the total epicardial and endocardial circumferences of the LV6

\section{Measurement of Capillary Density and Identification of Survival Transplantation Cells}

The effect of combined therapy on angiogenesis was evaluated by measuring the capillary density from the frozen sections stained with rabbit anti-factor VIII antibody (Zymed, 1:100) and a counterstaining with diaminobenzidine (DAB). A capillary vessel was defined as a vessel with a diameter less than $20 \mu \mathrm{m}$. The number of capillaries was counted under microscopy ( $\times 400$ magnification) for 10 random fields and presented as the mean of blood vessels per unit area $\left(0.2 \mathrm{~mm}^{2}\right)$ in the infarct area and at the border of the infarct area?

Cells transfected with GFP plasmid were immunostained for a-MHC (a protein marker of myocardium) by using anti-MHC (Berkeley, Richmond, CA, USA; 1:500 dilution) in myocardial frozen sections to verify which grafted cells were expressing GFP and to detect cardiac cell types. An 
Table 1 Cardiac Function

\begin{tabular}{lcccc}
\hline \hline & $\begin{array}{c}\text { LVSP } \\
(\mathrm{mmHg})\end{array}$ & $\begin{array}{c}\text { LVEDP } \\
(\mathrm{mmHg})\end{array}$ & $\begin{array}{c}+d p / d t \\
\left(\mathrm{mmHg} / \mathrm{s} \times 10^{3}\right)\end{array}$ & $\begin{array}{c}-d p / d t \\
\left(\mathrm{mmHg} / \mathrm{s} \times 10^{3}\right)\end{array}$ \\
\hline Baseline (before cell transplantation) & & & & \\
MI & $80 \pm 8$ & $20 \pm 1.3$ & $4.5 \pm 0.5$ & $4.1 \pm 0.4$ \\
$M I+C$ & $83 \pm 6$ & $20.1 \pm 0.6$ & $4.6 \pm 0.2$ & $4.3 \pm 0.2$ \\
$M I+T$ & $79 \pm 11$ & $20.3 \pm 0.9$ & $4.4 \pm 0.6$ & $3.9 \pm 0.3$ \\
MI+T+C & $81 \pm 9$ & $20 \pm 1.0$ & $4.5 \pm 0.5$ & $4.2 \pm 0.1$ \\
Four weeks after cell transplantation & $82 \pm 8$ & $20.1 \pm 1.3$ & $4.5 \pm 0.5$ & $4.1 \pm 0.4$ \\
MI & $100 \pm 6^{\#}$ & $18 \pm 0.6^{\#}$ & $5.2 \pm 0.2^{\#}$ & $5.2 \pm 0.2^{\#}$ \\
$M I+C$ & $99 \pm 11^{\#}$ & $17.6 \pm 0.9^{\#}$ & $5.3 \pm 0.6^{\#}$ & $5.1 \pm 0.3^{\#}$ \\
$M I+T$ & $119 \pm 9^{\#, *}$ & $12 \pm 1.0^{\#, *}$ & $7.2 \pm 0.5^{\#, *}$ & $7.2 \pm 0.1^{\#, *}$ \\
$M I+T+C$ & & &
\end{tabular}

LVSP, left ventricular systolic pressure; LVEDP, left ventricular end-diastolic pressure; $\pm d P / d t$, rate of peak left ventricular systolic pressure rise; $M I$, myocardial infarction; $M I+C, M I$ and cell transplantation; $M I+T, M I$ and transmyocardial revascularization. ${ }^{\#} p<0.01$ vs $M I ; * p<0.01$ vs $M I+C$ and $M I+T$.

Table 2 Weight Parameters

\begin{tabular}{lccccc}
\hline \hline & $\begin{array}{c}B W \\
(\mathrm{~g})\end{array}$ & $\begin{array}{c}\text { Heart weight } \\
(\mathrm{mg})\end{array}$ & $\begin{array}{c}\text { Heart weight/BW } \\
(\mathrm{mg} / \mathrm{g})\end{array}$ & $\begin{array}{c}L V W \\
(\mathrm{mg})\end{array}$ & $\begin{array}{c}L V W / B W \\
(\mathrm{mg} / \mathrm{g})\end{array}$ \\
\hline$M I$ & $315 \pm 7$ & $1,321 \pm 78$ & $4.4 \pm 0.8$ & $945 \pm 95$ & $3.0 \pm 0.3$ \\
$M I+C$ & $311 \pm 8$ & $1,290 \pm 43^{\#}$ & $4.1 \pm 0.2^{\#}$ & $803 \pm 26^{\#}$ & $2.6 \pm 0.1^{\#}$ \\
$M I+T$ & $309 \pm 9$ & $1,282 \pm 50^{\#}$ & $4.1 \pm 0.2^{\#}$ & $799 \pm 28^{\#}$ & $2.6 \pm 0.1^{\#}$ \\
$M I+C+T$ & $309 \pm 4$ & $1,178 \pm 168^{\#, *}$ & $3.7 \pm 0.5^{\#, *}$ & $826 \pm 35^{\#, *}$ & $2.7 \pm 0.1^{\#, *}$ \\
\hline
\end{tabular}

$B W$, bodyweight; $L V W$, left ventricular weight; $L V W / B W$, ratio of $L V W$ and $B W$. Other abbreviations see in Table 1.

${ }^{\#} p<0.01$ vs $M I ;{ }^{*} p<0.05$ vs $M I+C$ and $M I+T$.

hour later, cells were counterstained with DAB. After rinsing with PBS, the tissue section was examined and photographed under both fluorescent and light microcopy. Because GFP is a 238 -amino acid polypeptide ( 27kDa) and gap-junction channels admit the passage of small molecules $(<\sim 1 \mathrm{kDa})$, it is impossible for GFP to move between neighboring cells.

\section{Cell Survival Analysis}

Fifty cross-sections of the infarct region, taken at $100 \mu \mathrm{m}$ intervals and at a sectioning thickness of $7 \mu \mathrm{m}$, were imaged by using a Leica DAMIRB microscope (Wetzler, Germany) and a Spot RT digital camera (Diagnostic Instrument Inc, Sterling Heights, CA, USA). Five fields per animal were analyzed in a blinded fashion at $\times 400$ by using Metamorph Software. A cell survival index was calculated for each image as the ratio of the total number of detected microspheres and a mean cell survival ratio was calculated for each animal.

\section{Statistical Analysis}

Statistical analyses were performed with one-way ANOVA followed by SPSS software (SPSS Science, Chicago, IL, USA) analysis. Data (mean \pm SD) were considered statistically significant at a value of $\mathrm{p}<0.05$.

\section{Results}

\section{Left Ventricular Function}

Hemodynamic measurements of the LV are shown in Table 1. Six weeks after MI, the MI+T and MI $+\mathrm{C}$ group had an improvement of ventricular function, which was reflected by the increase in $\pm \mathrm{dP} / \mathrm{dtmax}$ and LVSP, as well as by the decrease in LVEDP compared with the MI group and self-baseline values $(\mathrm{p}<0.01)$. Moreover, better results were achieved for the $\mathrm{MI}+\mathrm{T}+\mathrm{C}$ group. These results

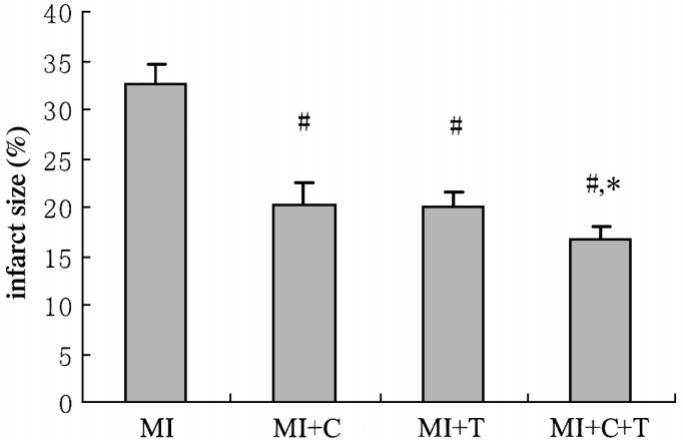

Fig 2. Infarct size. ${ }^{*} \mathrm{p}<0.01$ vs myocardial infarct (MI). ${ }^{*} \mathrm{p}<0.01$ vs $\mathrm{MI}$ and cell transplantation $(\mathrm{MI}+\mathrm{C})$ and $\mathrm{MI}$ and transmyocardial revascularization $(\mathrm{MI}+\mathrm{T})$.

showed that both systolic and diastolic functions were well preserved in the cell transplantation rats pretreated with TMR after MI.

\section{Left Ventricular Remodeling: Weight Parameters and Infarct Size}

Table 2 summarizes the changes of left ventricular weight and the ratio of the left ventricular weight to bodyweight. Six weeks after MI, there were no differences in bodyweight among the 3 groups, however, the left ventricular weight and ratio of the left ventricular weight to bodyweight were significantly decreased in the MI+T and $\mathrm{MI}+\mathrm{C}$ group compared with the MI group $(\mathrm{p}<0.01)$, suggesting that compensatory myocardial hypertrophy might have occurred in the non-ischemic myocardial tissue after MI. However, the ratio of the left ventricular weight to bodyweight was significantly decreased in the $\mathrm{MI}+\mathrm{T}+\mathrm{C}$ group. Fig 2 shows the effects of cell transplantation and 

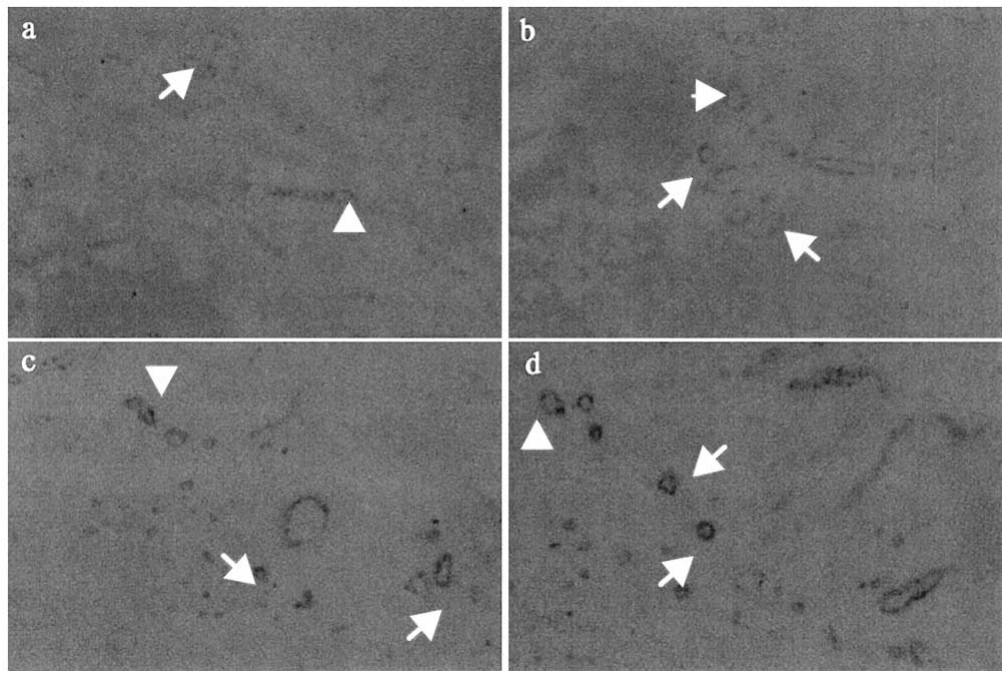

Fig 3. Immunohistochemical staining of factor VIII in the infarct myocardium of the myocardial infarct (MI) group (a), the MI and transmyocardial revascularization (MI+T) group (b), the MI and cell transplantation $(\mathrm{MI}+\mathrm{C})$ group $(\mathrm{c})$, and the $\mathrm{MI}+\mathrm{T}+\mathrm{C}$ group (d).

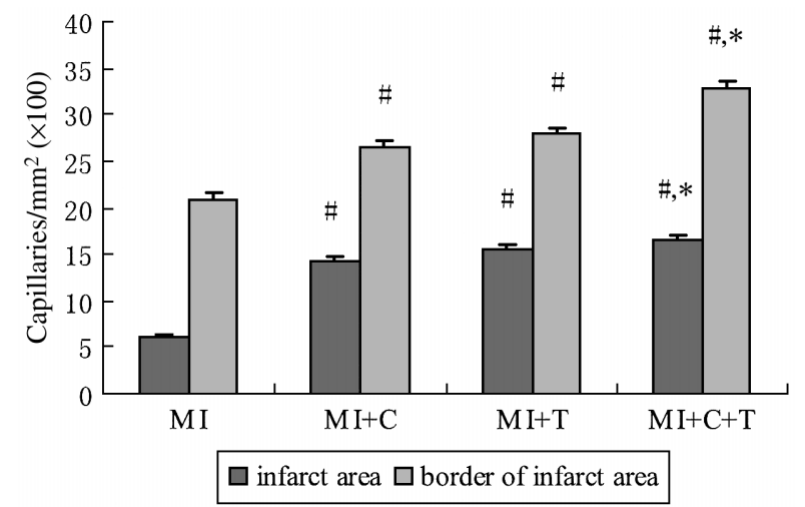

Fig 4. Capillary densities in the infarct area and border of the infarct area. ${ }^{*} \mathrm{p}<0.01$ vs myocardial infarct (MI); $* \mathrm{p}<0.01$ vs MI and cell transplantation $(\mathrm{MI}+\mathrm{C})$ and $\mathrm{MI}$ and transmyocardial revascularization $(\mathrm{MI}+\mathrm{T})$.

TMR on infarct area in rats. The infarct area was more significantly reduced in the $\mathrm{MI}+\mathrm{T}+\mathrm{C}$ group than in the $\mathrm{MI}+$ $\mathrm{T}$ or the $\mathrm{MI}+\mathrm{C}$ groups $(\mathrm{p}<0.01)$. There was no significant differences among the $\mathrm{MI}+\mathrm{T}$ and $\mathrm{MI}+\mathrm{C}$ groups. These data indicated that groups treated with cell transplantation but pretreated with TMR significantly reduced not only the severity of left ventricular hypertrophy, but also the area of infarction in the rats with MI.

\section{Capillary Density}

The angiogenic effect was analyzed by counting capillary stained VIII factors in sections of infarct myocardium obtained 6 weeks following the MI (Fig 3). Capillary density in areas of infarction was significantly greater in the $\mathrm{MI}+\mathrm{T}+\mathrm{C}$ group than in the $\mathrm{MI}+\mathrm{C}$ and the $\mathrm{MI}+\mathrm{T}$ groups $(\mathrm{p}<0.01)$. There was no significant differences among the $\mathrm{MI}+\mathrm{T}$ and $\mathrm{MI}+\mathrm{C}$ groups (Fig 4). This was also the case for the borders of infarct areas. There was a positive correlation between angiogenesis and TMR in terms of therapy for myocardial infarct-transplanted cells. It indicated that the occurrence of angiogenesis in infarcted myocardium might be subsequently induced by TMR and grafted cells. These new vessels might increase the perfusion in and to the ischemic myocardium.

\section{Identification of Transplantation Cells and Cell Survival Analysis}

Frozen sections prepared from MI areas after 4 weeks of cell grafts showed GFP-positive spots under fluorescent microscopy. Moreover, those GFP-positive cells were also a-MHC positive under light microscopy. Cross-sections from other areas of the heart did not show any GFP-positive anda actin-positive cells. Therefore, the grafted cells were not only survived but they also formed cardiac cells in injured myocardium. The cell survival index analysis showed a significantly greater number of islands of GFPpositive and a-MHC positive cells within the infarct myocardium appearing in sections of the $\mathrm{MI}+\mathrm{T}+\mathrm{C}$-treated groups than in the MI+C-treated groups ( $<<0.001 ;$ Figs 5,6). No GFP-positive spots were founded in the capillaries. The results indicate that more implanted cells survived in the infarct myocardium and differentiated into cardiac cell types but not into the endodermis type. Also, because GFP is a 238 -amino acid polypeptide $(\sim 27 \mathrm{kDa})$ and gap-junction channels admit the passage of small molecules $(<\sim 1 \mathrm{kDa})$, it is impossible for GFP to move between neighboring cells. In contrast, no ectopic cells or tissues were found in the sections that were GFP-positive spots or that werea-MHC positive spots.

\section{Discussion}

Compared with conventional mechanical and surgical therapy strategies, cell transplantation represents a novel therapy for patients with ischemia and left ventricular dysfunction. Although this cellular cardiomyoplasty therapy is already being investigated in clinical trials, much remains unknown about this new therapy. Others studies have speculated that persistent ischemia in the infarct territory is a potential contributor to implanted cell loss, which could consequently limit the efficacy of this therapy9,10 Supporting this hypothesis, the present study demonstrated pretreatment with TMR before cell transplantation to observe: (1) improvement of cardiac function; (2) vascularization of the infarct area; and (3) transplanted cell survival.

The present study showed that the improvement of cardiac function was even greater in the MI rats treated with TMR and cell transplantation, which suggested the importance of angiogenic therapy as an assistant to cellular cardiomyoplasty. Many studies have proven TMR to be 

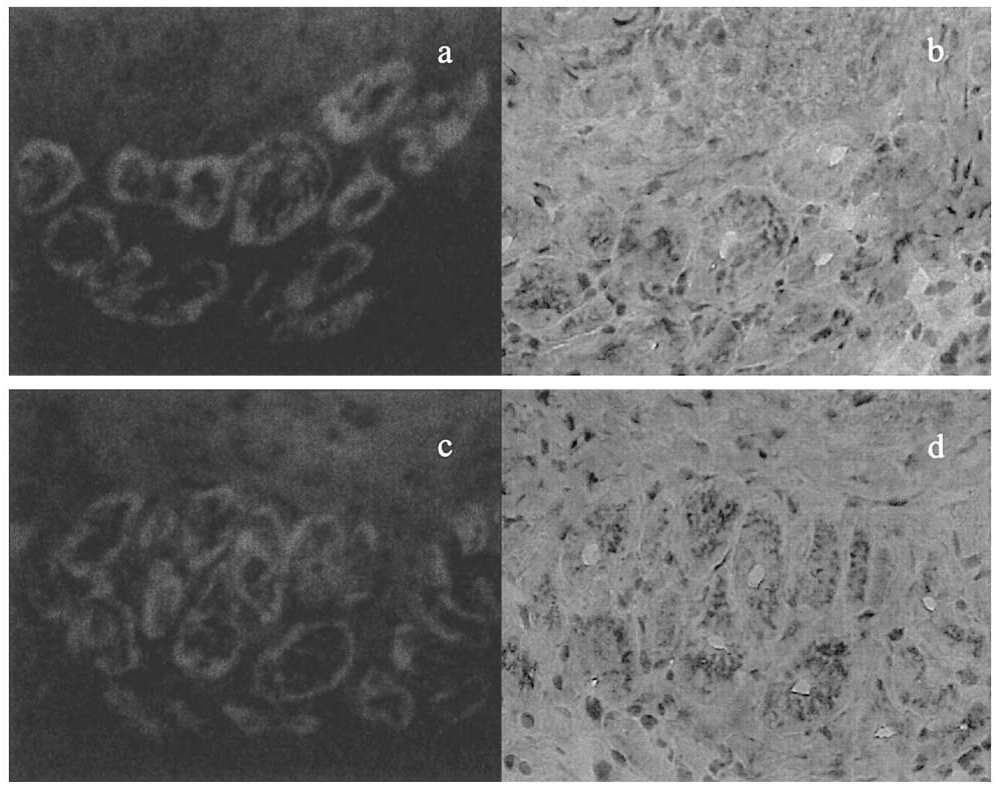

Fig 5. Green fluorescent protein-positive cells within the infarct myocardium (border of the infarct area) appeared a-myosin heavy chain (a protein marker of myocardium) positive in sections of the myocardial infarct and cell transplantation $(\mathrm{MI}+\mathrm{C})$ group $(\mathrm{a}, \mathrm{b})$ and the myocardial infarct, transmyocardial and cell transplantation $(\mathrm{MI}+\mathrm{T}+\mathrm{C})$ group $(\mathrm{c}, \mathrm{d})$.

effective in the treatment of refractory angina of myocardial infarct becausee of the angiogenic effect 11 One study indicated that the intramyocardial injection of stem cells prolonged the upregulation of vascular endothelial growth factor (VEGF) expression, which might contribute to further enhancement of angiogenesis? In the present study, it was found that the transplantation of EGs alone or EGs plus TMR significantly increased the density of capillaries, especially at the border of the infarct area, although they partly differentiated into cardiac-like cells. In pig experiments, Van Meter et al showed that transplantation of human cardiomyocytes induced the growth of new blood vessels in the grafted area and host myocardium! ${ }^{12}$ A possible explanation of the angiogenesis effect is that cells used for transplantation serve as platforms for the release of cardioprotective factors such as VEGFs, which prolong the upregulation of VEGF expression. TMR-induced angiogenesis promoted perfusion in the MI zone and provided the grafted cells with a blood supply, which removed cellular debris after myocardial injury and enhanced survival and regeneration of grafted cells. Subsequently, this regeneration attenuated infarct size and improved heart function. In addition, the increase in capillary density, if it occurs in a clinical setting, might be of significance for the quality of life in patients with heart failure.

The data in our research showed that there was a significant reduction of infarct size in MI rats treated with TMR and cell transplantation. Reduction of infarct size was a result of the regeneration of myocardium from engrafted cells, which could prevent overstretching of ventricles and preserve myocardium contractile function ${ }^{13}$ Therefore, combined therapy significantly improved isometric contractility.

Also, we allowed an interval of 2 weeks between the TMR and cell implantation, based upon our prior observation of the time intervals required for maximal blood vessel development following TMR. The present study data do not exclude the possibility that longer time intervals might not adequately provide for the development of nutritive vasculature to support cell implantation in infracted territories. The present studies also do not exclude the potential

\section{cell survival index}

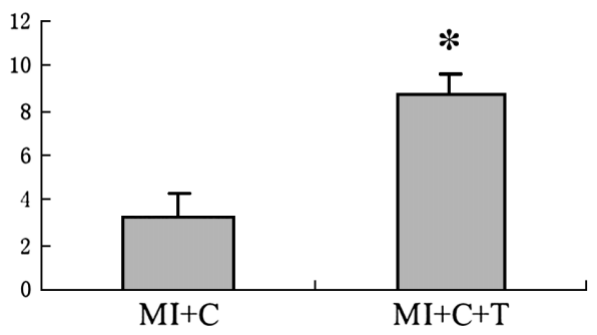

Fig 6. Cell survival index. ${ }^{*} \mathrm{p}<0.001$. MI $+\mathrm{C}$, myocardial infarct and cell transplantation; $\mathrm{T}$, transmyocardial transplantation.

role of the vasodilator or antiapoptotic properties of VEGF in enhancing the survival of cells implanted at these shorter intervals. It is, however, important that "prevascularization" occurs so that it enhances the efficacy of cell cardiomyoplasty.

EGs as a type of pluriopotent stem cell in terms of their potential contribution to cardiomyocyte replacement therapies for injured myocardium. Our morphological data confirmed that the grafted cell could survive in injured myocardium by the identification of GFP-positive cells in an implanted heart. Although the cells used for cell transplantation in the present study experiments were earlydifferentiated cardiac-like cells from EGs, the formation of the ectopic tissue as teratomas in the myocardium at the operation site was not found. Engrafted donor cells were observed to be aligned and tightly juxtaposed with host cardiomyocytes. Although the exact size of GFP-positive cells were not measure, it was found that the shape and size of mature GFP-positive myocytes did not significantly differ from those of host cardiomyocytes as observed under a microscope. This is consistent with the results reported by other studies that involved transplantation of cardiomyocytes differentiated from embryonic stem cells ${ }^{14}$ or dissected from embryos 15 Some opinions see fewer ethical problems in using aborted fetuses rather than discard preimplantation embryos to provide a cell source for cell 
therapy use ${ }^{16}$ In contrast, GFP-positive cells are not found to be in capillaries, and so no grafted cells transdifferentiated into the endodermis.

A decrease in infarct size, improved function and survival of donor cells can explain how the differentiated new cell types work functionally and normally after transplantation.

The present study showed that EG transplantation was not only able to regenerate injured myocardium but it also allowed an improvement of cardiac function in post-MI animals. Pretreatment of an infarct region of the heart with angiogenesis induced by TMR enhanced the efficacy of a cell graft. This synergistic approach resulted in a stronger neovascularizatiom in infarct myocardium and greater improvement of damaged heart function. The present study data may provide useful and safe information for future clinical cell transplantations in patients suffering from heart failure after MI.

\section{References}

1. Ogawa K, Yaoita H, Okamoto M, Ikeda K, Shichishima T, Ohto H, et al. Transient improvement of left ventricular function after peripheral blood stem cell transplantation in a patient with myelodysplastic syndrome and dilated cardiomyopathy. Circ J 2004; 68: 958-960.

2. Schwartz Y, Kornowski R. Progenitor and embryonic stem cell transplantation for myocardial angiogenesis and functional restoration. Eur Hear J 2003; 24: 404-411.

3. Svorkdal N. Treatment of inoperable coronary disease and refractory angina: Spinal stimulators, epidurals, gene therapy, transmyocardial laser, and counterpulsation. Semin Cardiothorac Vasc Anesth 2004; 8: $43-58$.

4. Honjo O, Ishino K, Matsumoto T, Yamamoto S, Asai T, Kohmoto T, et al. Digital radiographic quantification of myocardial blood flow around a transmyocardial laser channel in rabbit harts. Circ J 2005; 69: $488-492$.

5. Min JY, Yang Y, Sullivan MF, Ke Q, Converso KL, Chen Y, et al. Long-term improvement of cardiac function in rats after infarction by transplantation of embryonic stem cells. $J$ Thorac Cardiovasc
Surg 2003; 125: 361-369.

6. Mulder P, Boujedaini H, Richard V, Henry JP, Renet S, Munter K, et al. Longterm survival and hemodynamics after endothelin-a receptor antagonism and angiotensin-converting enzyme inhibition in rats with chronic heart failure: Monotherapy versus combination therapy. Circulation 2002; 106: 1159-1164.

7. Pfeffer JM, Pfeffer MA, Fletcher PJ, Braunwald E. Progressive ventricular remodeling in rats with myocardial infarction. Am J Physiol 1991; 260: H1406-H1414.

8. Siminiak T, Kalawski R, Fiszer D, Jerzykowska O, Rzezniczak J, Rozwadowska N, et al. Autologous skeletal myoblast transplantation for the treatment of postinfarction myocardial injury: Phase I clinical study with 12 months of follow-up. Am Heart J 2004; 148: 531 537.

9. Tomita S, Li RK, Weisel RD, Mickle DA, Kim EJ, Sakai T, et al. Autologous transplantation of bone marrow cells improves damaged heart function. Circulation 1999; 100(Suppl II): 247-256.

10. Peters NS, Green CR, Poole-Wilson PA, Severs NJ. Cardiac arrhythmogenesis and gap junction. J Mol Cell Cardiol 1995; 27: 37-44.

11. Chu V, Kuang J, McGinn A, Giaid A, Korkola S, Chiu RC. Angiogenic response induced by mechanical transmyocardial revascularization. J Thorac Cardiovasc Surg 1999; 118: 849-856.

12. Van Meter $\mathrm{CH}$, Claycomb WC Jr, Delcarpio JB, Smith DM, deGruiter H, Smart F, et al. Myoblast transplantation in the porcine model: A potential technique for myocardial repair. J Thorac Cardiovasc Surg 1995; 110: 1142-1148.

13. Muller EJ, Whittaker P, Kloner RA. Survival and development of neonatal rat cardiomyocytes transplanted into adult myocardium. $J$ Mol Cell Cardiol 2003; 34: 107-116.

14. Klug MG, Soonpaa MH, Koh GY, Field LJ. Genetically selected cardiomyocytes from differentiating embryonic stem cells form stable intracardiac grafts. J Clin Invest 1996; 98: 216-224.

15. Etzion S, Battler A, Barbash IM, Cagnano E, Zarin P, Granot Y, et al. Influence of embryonic cardiomyocyte transplantation on the progression of heart failure in a rat model of extensive myocardial infarction. J Mol Cell Cardiol 2001; 33: 1321-1330.

16. Heba G, Krzeminski T, Porc M, Grzyb J, Ratajska A, DembinskaKiec A. The time course of tumor necrosis factor-alpha, inducible nitric oxide syntheses and vascular endothelial growth factor expression in an experimental model of chronic myocardial infarction in rats. J Vasc Res 2001; 38: 288-300. 